\title{
Attachment and problematic Facebook use in adolescents: The mediating role of metacognitions
}

\author{
CLAUDIA MARINO ${ }^{1,2 *}$, TATIANA MARCI ${ }^{1}$, LUCREZIA FERRANTE ${ }^{3}$, GIANMARCO ALTOË ${ }^{1}$, ALESSIO VIENO ${ }^{1}$, \\ ALESSANDRA SIMONELLI ${ }^{1}$, GABRIELE CASELLI ${ }^{2,4,5}$ and MARCANTONIO M. SPADA ${ }^{2}$
${ }^{1}$ Dipartimento di Psicologia dello Sviluppo e della Socializzazione, Università degli Studi di Padova, Padova, Italy
${ }^{2}$ Division of Psychology, School of Applied Sciences, London South Bank University, London, UK
${ }^{3}$ Dipartimento di Storia, Società e Studi sull'uomo, Università del Salento, Lecce, Italy
${ }^{4}$ Studi Cognitivi, Milano, Italy \\ ${ }^{5}$ Department of Psychology, Sigmund Freud University, Milano, Italy
}

(Received: September 20, 2018; revised manuscript received: January 17, 2019; accepted: January 27, 2019)

\begin{abstract}
Background and aims: Recent research used attachment theory and the metacognitive tenet as frameworks to explain problematic Facebook use (PFU). This study aims to test, in a single model, the role of different attachment styles and metacognitions in PFU among adolescents. Methods: Two separate studies were conducted in order to establish the link between security (Study 1) and insecurity (Study 2), metacognitions, and PFU. A total of 369 and 442 Italian adolescents (age: 14-20 years old) participated in Study 1 and Study 2, respectively. Results: Path analyses revealed the relative importance of different attachment dimensions with mother and father in predicting PFU and the mediating role of metacognitions between attachment styles and PFU. Discussion and conclusion: In conclusion, since attachment styles and PFU may significantly affect adolescents' development and well-being, the results of this study may provide some practical indications for researchers and practitioners.
\end{abstract}

Keywords: attachment, metacognitions, problematic Facebook use, adolescents

\section{INTRODUCTION}

In recent years, the use of social media has grown exponentially across the globe with Facebook reaching over two billion active users (Statista.com, 2017). Increasing research efforts have therefore focused on how the use, overuse, or problematic use of Facebook may affect people's well-being (Marino, Gini, Vieno, \& Spada, 2018a). It has been shown that social media like Facebook may have positive effects on young people's life, in terms of perceived social support, social trust, civic engagement, and political participation (Gil de Zúñiga, Jung, \& Valenzuela, 2012; Gil de Zúñiga, Molyneux, \& Zheng, 2014; Lenzi et al., 2015; Valenzuela, Park, \& Kee, 2009). Nevertheless, concerns have been rising about the negative impact of maladaptive Facebook use. For example, research evidence has outlined positive associations between Facebook use and low self-esteem (Andreassen, Pallesen, \& Griffiths, 2017; Baturay \& Toker, 2017; Malik \& Khan, 2015), anxiety and depressive symptoms (Moreau, Laconi, Delfour, \& Chabrol, 2015; Seabrook, Kern, \& Rickard, 2016), poor academic performance (Huang, 2018; Liu, Kirschner, \& Karpinski, 2017), and relational conflict (Fox \& Moreland, 2015; Fox, Osborn, \& Warber, 2014; for a meta-analysis on this topic, see Marino et al., 2018a).

These findings have led to a growing concern that problematic Facebook use (PFU) may become a mental health problem. Some scholars have suggested that the use of social network sites (SNSs), including Facebook, may be characterized by addictive-like symptoms (Kuss \& Griffiths, 2011; Marino et al., 2018a). Nevertheless, addiction to SNSs has no status in the latest version of the Diagnostic and Statistical Manual of Mental Disorders and it is still not recognized as a mental disorder (Marino, Gini, Vieno, \& Spada, 2018b). However, several different definitions of Facebook addiction and consequently tools to measure this construct have been proposed in recent years (Andreassen \& Pallesen, 2014; Biolcati, Mancini, Pupi, \& Mugheddu, 2018; Griffiths, Kuss, \& Demetrovics, 2014). According to some researchers (e.g., Lee, Cheung, \& Thadani, 2012; Marino et al., 2016), the term Problematic Facebook Use refers to the maladaptive use of Facebook, which negatively impacts on personal, family, and/or professional life. Moreover, according to Caplan's generalized problematic Internet use (PIU) model (Caplan, 2010), PFU can be conceptualized in terms of preference for online social interactions, mood regulation, cognitive preoccupation, and compulsive use, resulting in negative consequences for users' life (Marino, Vieno, Altoè, \& Spada, 2017).

\footnotetext{
* Corresponding author: Claudia Marino; Dipartimento di Psicologia dello Sviluppo e della Socializzazione, Università degli Studi di Padova, via Venezia 8, Padova 35125, Italy; Phone: +39 049827 6402; Fax: +39 049827 6547; E-mail: claudia.marino@phd.unipd.it
}

This is an open-access article distributed under the terms of the Creative Commons Attribution-NonCommercial 4.0 International License, which permits unrestricted use, distribution, and reproduction in any medium for non-commercial purposes, provided the original author and source are credited, a link to the CC License is provided, and changes - if any - are indicated. 
A number of PFU correlates have been investigated including personality traits, motives for using Facebook, and selfesteem (Marino et al., 2018b) but less is known about the psychological mechanisms leading to PFU (e.g., Casale, Caplan, \& Fioravanti, 2016).

This study aims to investigate the association between attachment styles, metacognitions, and PFU among adolescents. Adolescents are considered to be the most active age group on social media and the most vulnerable to possible negative consequences of SNSs use including Facebook (Valkenburg \& Peter, 2011). Attachment theory has been used as a framework to explain engagement with Facebook in previous studies (e.g., Hart, Nailling, Bizer, \& Collins, 2015). Moreover, the role of metacognitions in predicting problematic Internet and Facebook use has been hypothesized in previous studies (e.g., Casale et al., 2016; Marino et al., 2016; Spada, Langston, Nikčević, \& Moneta, 2008), showing that metacognitions may drive the use of Facebook as a means for regulating emotions and cognitive preoccupation in PFU. Furthermore, each attachment style is considered to be associated with a specific pattern of thinking, feeling, and behaving (Caselli, Ruggiero, \& Sassaroli, 2017). For this reason, recently, the relationship between attachment and metacognition has been explored, emphasizing several correspondences between attachment styles and specific metacognitions (Caselli et al., 2017). This is the first study to test, in a sole model, the role of attachment styles and metacognition in explaining PFU among adolescents.

\section{Attachment styles and PFU}

Attachment has been defined as a system of internalized representations based on past relational experiences with significant figures that mediates close relationships, reflecting specific cognitions and emotions, and influencing how an individual interacts with acquaintances and strangers (Mikulincer \& Shaver, 2012): adolescents will tend to develop secure attachment styles when adults are able to be responsive, and insecure styles when parents are less sensitive.

According to traditional attachment theory, the quality of early relationships between child and caregivers shapes future relationships in the life cycle, particularly in adolescence and adulthood (Bowlby, 1969). Moreover, research has demonstrated that secure attachment and emotional connectedness with parents continue to play a prominent role for adolescents in the transition to autonomy and adulthood (Ryan \& Lynch, 1989). The cognitive, social, and emotional changes starting from middle childhood may impact the parent-child relationship (Lynch \& Cicchetti, 1997; Kerns, Schlegelmilch, Morgan, \& Abraham, 2005; Mayseless, 2005), making attachment representations increasingly elaborated and organized (Kerns \& Brumariu, 2016). Indeed, from middle childhood, adolescents became progressively more independent and self-aware, as they start to be involved in new social contexts outside the family. Hence, the emphasis of the attachment system shifts from proximity to psychological availability (Kerns \& Brumariu, 2016), and the perception of security is mostly maintained by the accessibility of the attachment figure and sensitivity that continue to be essential in maintaining attachment security also during adolescence (Allen et al., 2003). During this period, adolescents may direct attachment-related behaviors to new figures beyond parents (i.e., friends, teachers, and love partners). Indeed, using only the "alienation with peers" dimension, Assunção and Matos (2017) have recently showed that problematic Facebook users tend to be higher in alienation to peers than less problematic users, thus sustaining previous findings about the negative association between maladaptive use of the Internet and social life (e.g., Fox \& Moreland, 2015; Liu \& Kuo, 2007). Although peers become increasingly important as source of support from early to late adolescence, parents remain a key source of support also in young adulthood (Trinke \& Bartholomew, 1997). For this reason, the present studies are focused on attachment with parents.

Previous studies outlined that adolescents showing secure attachment with parents were more likely to have lower levels of PIU (e.g., Arpaci, Baloolu, Kozan, \& Kesici, 2017; Lei \& $\mathrm{Wu}, 2007)$, because they hold positive representations of themselves and others and tend to feel comfortable in social interactions, thus establishing positive relationships offline (e.g., Savc1 \& Aysan, 2016). On the contrary, adolescents showing insecure styles tended to be more engaged with Facebook as a result of their low levels of social skills (e.g., Kalaitzaki \& Birtchnell, 2014; JenkinsGuarnieri, Wright, \& Hudiburgh, 2012). For example, it has been argued that insecure people feeling anxious in real social situations tend to use the Internet to communicate online, thus avoiding social threats like shyness (e.g., Şenormanc1, Şenormanc1, Güçlü, \& Konkan, 2014).

For its intrinsic social nature, attachment has been studied across the life span (developing specific views), and several instruments for childhood, adolescence, and adulthood have been used in the context of Facebook use research to date. For example, the Inventory of Parent and Peer Attachment (IPPA; San Martini, Zavattini, \& Ronconi, 2009) was specifically developed to measure adolescent secure attachment quality with specific attachment figures (i.e., mother, father, and peers) during adolescence. Attachment quality has been operationalized in terms of trust, quality of communication, and feelings of alienation resulting from an unresponsive attachment figure. Using a different approach, Brennan, Clark, and Shaver (1998) have argued that insecure attachment is characterized by two main components: attachment anxiety and attachment avoidance. Attachment anxiety indicates how intensively an environmental or relational threat activates the attachment system, whereas attachment avoidance refers to the desire of closeness. People scoring high on attachment anxiety show hyperactivating strategies, attempting to achieve proximity, support, and love. In contrast, deactivating strategies, such as trying not to seek proximity, denying attachment needs, and avoiding closeness and interdependence in relationships, are observed in individuals with high levels of attachment avoidance (Brennan et al., 1998). It has been argued that these two dimensions of attachment may explain interpersonal differences observed both in offline and online interactions (Hart et al., 2015).

Jenkins-Guarnieri, Wright, and Johnson (2013) investigated how attachment style and personality traits were 
related to Facebook use and found a negative indirect effect of attachment style (through extraversion) on Facebook use in undergraduate students aged between 17 and 22 years. Nevertheless, despite the authors assessed attachment with the Experiences in Close Relationships - Revised Scale (Fraley, Waller, \& Brennan, 2000), which is designed to provide two different scores for avoidance and anxiety, they operationalized attachment as a single dimension (insecurity vs. security), thus its findings have been criticized (Hart et al., 2015). Another study (Oldmeadow, Quinn, \& Kowert, 2013) included attachment anxiety and attachment avoidance in the context of close adult relationships separately as predictors of Facebook use. Adults with high attachment anxiety were found to use Facebook more frequently, especially when feeling negative emotions, and were more worried about the impression given on Facebook. Conversely, people high in attachment avoidance were found to use Facebook less frequently and to be less concerned about how others perceive them (Oldmeadow et al., 2013).

Moreover, Hart et al. (2015) have tried to explain why anxiety and avoidance can predict different patterns of Facebook use. Attachment anxiety was found to be associated with more intense activity (more frequent posts, a wide range of topics, more tags received by friends, more comments on profiles, etc.), feedback sensitivity, feedback seeking, received attention, and a lower inclination to privacy. Thus, it appears that attachment anxiety may compel to try to obtain positive feedback from others showing more attention-seeking behaviors (Hart et al., 2015). In the case of attachment avoidance, authors found controlled and contented Facebook patterns of use. More specifically, the behavior of the individuals high in attachment avoidance seems to reflect their desire to avoid intimacy and maintain a safety distance (Hart et al., 2015).

Recently, a study by Monacis, de Palo, Griffiths, and Sinatra (2017a) confirmed the role of attachment in predicting online behaviors, including SNSs use in adolescents and adults (age range: 16-40 years). Attachment anxiety seems to put an individual at a major risk of a problematic use, whereas avoidance may represent a protective factor. According to researchers' interpretation of these findings, excessive desires and efforts for acceptance in people high in attachment anxiety may lead them to use Facebook in order to obtain approval, thus making them more likely to show negative patterns of Facebook use. On the other hand, discomfort for intimacy, which is the characteristic of avoidant people, tends to reduce Facebook activity (Monacis et al., 2017a). On the whole, there has been little research on the relationship between attachment toward mother and father and PFU during adolescence (Monacis, De Palo, Griffiths, \& Sinatra, 2017b). This is quite surprising considering that adolescence represents the stage in which quality of attachment plays a prominent role in socio-emotional adjustment and children typically start using, heavily, social media.

\section{Metacognitions and PFU}

The metacognitive tenet (Wells \& Matthews, 1996) emphasizes the role of metacognitions in almost all psychological problems (for a review, see Wells, 2013). The model states that psychological problems are exacerbated and maintained by maladaptive styles of coping with thoughts and emotions, such as perseverative thinking like worry and rumination, monitoring, and thought suppression. These coping styles are derived from underlying metacognitions, which have been defined as "the information individuals hold about their own cognition and internal states, and about coping strategies that impact both" (Wells, 2000). Wells and Cartwright-Hatton (2004) assessed metacognitions through five factors: (a) positive beliefs about worry (measuring beliefs that perseverative thinking is useful), (b) negative beliefs about thoughts (measuring beliefs that perseverative thinking is dangerous), (c) cognitive confidence (in one's own attention and memory), (d) beliefs about the need to control thoughts, and (e) cognitive self-consciousness (assessing the tendency to self-focus attention and to monitor thoughts).

Spada et al. (2008) first identified the role of metacognitions in PIU. They argued that metacognitions are responsible for the intensification of negative emotions, which in turn increase the likelihood to engage in PIU as a means of cognitive-affective self-regulation (Spada et al., 2008). Similarly, a recent study (Casale et al., 2016) suggested that positive metacognitions, in terms of escapism and controllability, were related to PIU. A further study, which focused on PFU among young adults (Marino et al., 2016), emphasized that metacognitions may play a similar role in PFU. For example, people having negative beliefs about thoughts were found to be more likely to engage in PFU, using social networks to regulate emotions and cognitions (Caplan, 2010). Moreover, the authors speculated that PFU itself could serve as a means to worry and ruminate about interactions with Facebook friends and reactions received on Facebook (Marino et al., 2016).

\section{Aims of this study}

This study aims to test a model designed to assess the contribution of attachment styles and metacognitions on PFU among adolescents. The conceptual model is presented in Figure 1 and the following hypotheses directly derive from the literature and sustain the model structure.

First, as reviewed above (see "Attachment styles and PFU" section), several attachment styles have been found to be associated with different patterns of Facebook use and with PFU (e.g., Lin, 2015). Nevertheless, previous studies were limited in two main ways. First, their results seem to be affected by the lack of clarity on how discriminate problematic Facebook users from highly engaged but non-problematic Facebook users. Indeed, different profiles of Facebook users were identified based on time spent on Facebook, frequency of interactions (e.g., Jenkins-Guarnieri et al., 2012; Lin, 2015), general activities (i.e., frequency of commenting and liking behaviors), and tendency toward privacy (Hart et al., 2015) rather than using a measure for PFU. Second, some studies considered attachment as a single dimension (insecurity vs. security; Jenkins-Guarnieri et al., 2012; Schimmenti, Passanisi, Gervasi, Manzella, \& Famà, 2014), whereas other researchers outlined the importance of considering attachment dimensions separately, finding independent effects (Hart et al., 2015; Oldmeadow et al., 2013). 


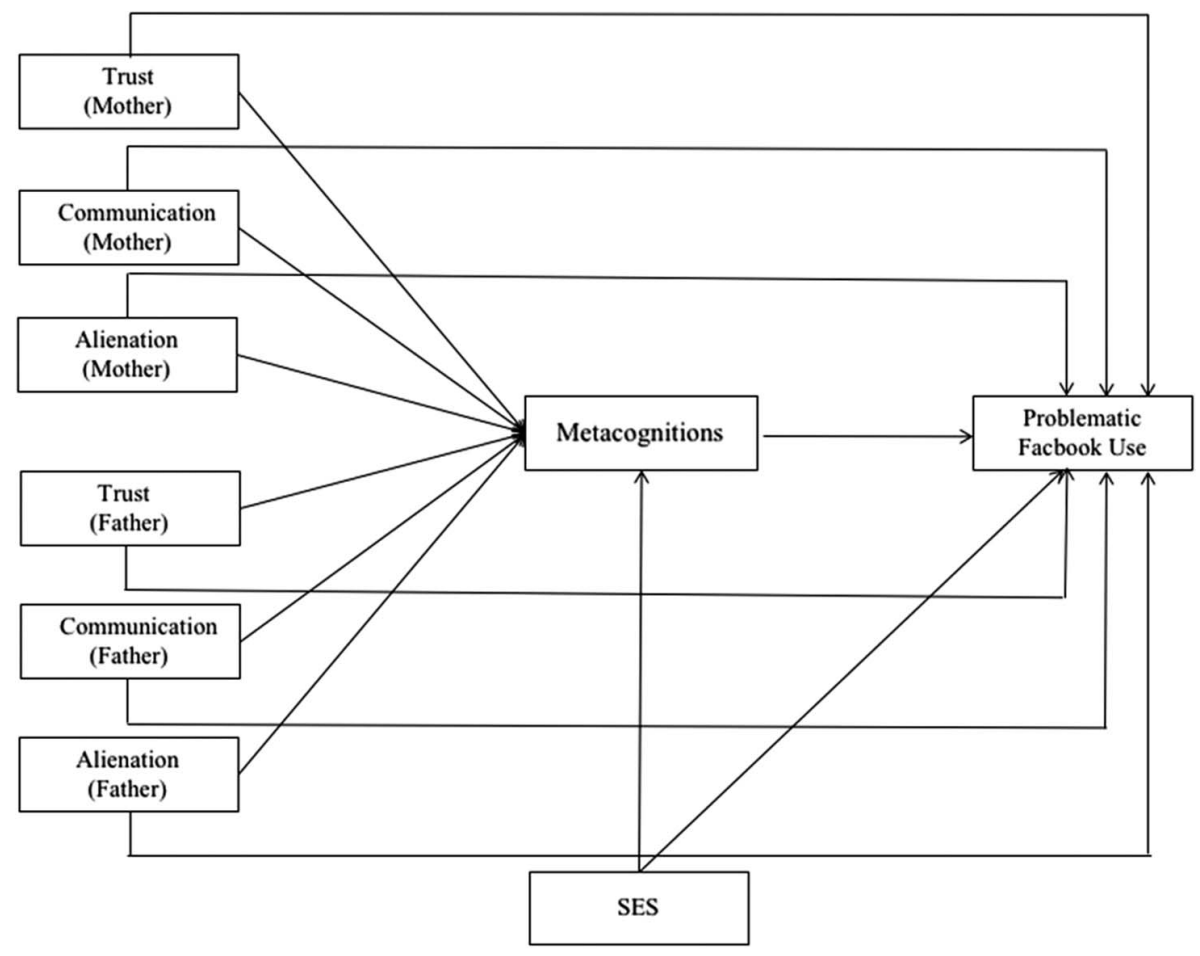

Figure 1. The theoretical model of problematic Facebook use developed for Study 1. Note. SES: socioeconomic status

The present research will explore the role of different attachment-related dimensions separately in predicting PFU. More specifically, a three-dimension (trust, communication, and alienation) model of adolescents' attachment with parents (Armsden \& Greenberg, 1989) will be used to assess security in attachment (Study 1). Following this, we will focus on attachment anxiety and avoidance to assess insecurity in attachment (Study 2).

Hypothesis 1: PFU will be associated with attachment with mother and father in terms of trust, communication, and alienation (Study 1) and in terms of anxiety and avoidance (Study 2).

Second, it has been demonstrated that metacognitions are involved in several problematic behaviors, including traditional addictive behaviors (e.g., problem drinking and smoking), established behavioral addictions (i.e., gambling), and potential behavioral addiction such as PIU and problematic gaming (Mansueto et al., 2016; Spada \& Caselli, 2017; Spada, Caselli, \& Wells, 2009; Spada, Nikčević, Moneta, \& Wells, 2007). Therefore, we want to test whether metacognitions are directly linked to PFU in adolescents:

Hypothesis 2: PFU will be positively associated with metacognitions.

Third, based on suggestions by Casale et al. (2016), it is likely that metacognitions play a mediating role in the relationships between potential risk factors and PIU in general. Caselli et al. (2017) have indeed suggested that attachment styles are strictly linked to the formation of metacognitions. Despite the lack of empirical research in this specific field to date, it has been proposed that insecure attachment styles lead to the development of maladaptive metacognitions, which in turn drive the engage in dysfunctional cognitive and emotional regulation strategies such as worry, rumination, threat monitoring, and suppression, thus obstructing new information processing (Caselli et al., 2017; Esbjørn, Bender, Reinholdt-Dunne, Munck, \& Ollendick, 2012; Spada et al., 2012). On the other hand, attachment security allows children to consider negative thoughts and emotions as temporary events, and explore the world with attention flexibility (Caselli et al., 2017). As mentioned above, both PIU and PFU are typically considered maladaptive self-regulatory strategies in their own right (Akbari, 2017; LaRose, Lin, \& Eastin, 2003; Marino et al., 2018a; Spada et al., 2008). From this point of view, it is possible to suppose that metacognitions may play a mediating role in the relationship between attachment styles and PFU among adolescents.

Hypothesis 3: The relationship between attachment and PFU will be mediated by metacognitions.

Although a few studies have analyzed some of the current associations, to date, no attempt has been made to investigate the possible links between different attachment patterns to mother and father (security - Study1 and insecurity - Study 2), metacognitions, and PFU among adolescents in a single model.

\section{METHODS}

\section{Participants}

In Study 1, participants were 369 Italian students aged between 14 and 20 years.

Of these, $83(22.5 \%)$ students declared not to have a Facebook account and were excluded from data analyses. Questionnaires with more than $20 \%$ of missing data in 
relevant scales $(N=15)$ were not included in the data analyses. The remaining missing values were imputed for each participant based upon the participant's mean score on the considered scale (rounding off to the closest integer, with respect to the metric of each measure). The final sample included 271 students $(67.9 \%$ girls $)$ aged from 14 to 20 years (mean age $=17.02$ years, $S D=1.56$ ). Socioeconomic background was measured through the Family Affluence Scale (FAS; Boyce, Torsheim, Currie, \& Zambon, 2006). The majority of participants belonged to families with middle (35.8\%) and upper income $(63.8 \%)$.

In Study 2, participants were 442 Italian students aged between 14 and 20 years. Consistent with Study 1, questionnaires completed by students declaring not to have a Facebook account $(22.6 \%, N=100)$, and questionnaires with more than $20 \%$ of missing data in relevant scales $(N=6)$, were not included in the data analyses. The remaining missing values were imputed using the same procedure as in Study 1. The final sample included 336 students $(54.76 \%$ girls) aged from 14 to 20 years (mean age $=16.22$ years, $S D=1.41)$. The majority of participants belonged to families with middle (29\%) and upper income (68.9\%).

\section{Procedure (Study 1 and Study 2)}

The two samples were convenient and self-selected samples. Anonymous self-report questionnaires were completed online in school computer rooms. Data were collected during a regular school day in about $30 \mathrm{~min}$. Before administration, participants were told that they could withdraw from the study at any time without consequences and that their participation would remain confidential. After the completion of the questionnaires, students were thanked for their participation and researchers answered any students' questions. In Study 1, all participants completed a sociodemographic form (date of birth, gender, and the FAS; Boyce et al., 2006), and three other measures including: (a) the Italian version of the IPPA (San Martini et al., 2009) to evaluate attachment style, (b) the Problematic Facebook Use Scale (PFUS; Marino et al., 2017) to measure participants' level of PFU, and (c) the Italian version of the Metacognitions Questionnaire-30 (MCQ-30; Quattropani, Lenzo, Mucciardi, \& Toffle, 2014) to evaluate maladaptive metacognitions. In Study 2, participants completed the same questionnaires with the exception of the IPPA. Thus, in order to evaluate the attachment bond (anxiety and avoidance), the 12-item Italian version of Experience in Close Relationship Revised for Children and Adolescence separately for mother and father (Brenning, Van Petegem, Vanhalst, \& Soenens, 2014) was administered.

\section{Measures}

Attachment (Study 1). The Italian version of IPPA (Guarnieri, Ponti, \& Tani, 2010; San Martini et al., 2009) was used to measure the attachment quality with specific attachment figures (i.e., mother and father) and peers. The IPPA comprises three subscales for each attachment figure, namely, trust (10 items; e.g., "I trust my mother/father"), quality of communication (9 items; e.g., "When we discuss things, my mother/father considers my point of view"), and feelings of alienation resulting from an unresponsive attachment figure (5 items; e.g., "I feel angry with my mother/father"). Each item was rated on a 5-point scale ranging from (1) "completely untrue" to (5) "completely true." Scores across items were averaged to obtain a continuous score for each factor. Higher scores indicate higher levels of trust, communication, and alienation, respectively. The questionnaire possesses evidence of validity and reliability in adolescents aged between 12 and 20 years across different countries including Italy (Guarnieri et al., 2010). For the purpose of this study, participants were asked to fill in the mother and father forms. Polychoric Cronbach's $\alpha$ s were $.93[95 \% \mathrm{CI}=0.92-0.94], .91 \quad[95 \% \mathrm{CI}=0.89$ $0.93]$, and .80 [95\% CI $=0.76-0.84]$ for trust, communication, and alienation subscales, respectively, pertaining to mother, and .94 [95\% CI $=0.93-0.95], .92$ [95\% CI $=0.90$ 0.93], and .94 [95\% CI $=0.93-0.95]$ for trust, communication, and alienation subscales, respectively, pertaining to father.

Attachment (Study 2). The shortened form of Experiences in Close Relationships - Revised Child's Version (ECR$\mathrm{RC}$; Brenning et al., 2014) was used to measure anxiety (e.g., "I worry that my father/mother does not really love me") and avoidance (e.g., "I prefer not to tell my father/ mother how I feel deep down") with respect to attachment with mother and father in children and adolescents. The ECR-RC consists of six items for each factor (i.e., anxiety and avoidance) for the two attachment figures (i.e., mother and father). Items were rated on a 7-point scale ranging from (1) "completely disagree" to (7) "completely agree." Scores across items were averaged to obtain different scores for anxiety and avoidance for attachment with both mother and father. Higher score denoted higher levels of anxiety and avoidance. The ECR-RC has been shown to have good factor structure in children and adolescents aged between 8 and 20 years (Brenning et al., 2014; Marci, Moscardino, \& Altoè, 2018). Moreover, external validity has been supported by the associations found with other attachment representational measures (i.e., the Relationship Questionnaire), depressive symptoms, and emotion regulation strategies (Brenning, Soenens, Braet, \& Bosmans, 2011, 2012). In this study, polychoric Cronbach's $\alpha$ s were .95 [95\% CI = $0.94-0.96]$ and $.90[95 \% \mathrm{CI}=0.88-0.92]$ for the subscales of anxiety and avoidance, respectively, pertaining to mother, and $.97[95 \% \mathrm{CI}=0.97-0.98]$ and $.89[95 \% \mathrm{CI}=0.87=$ $0.91]$ for the subscales of attachment anxiety and avoidance, respectively, pertaining to father.

Problematic Facebook use. The PFUS (Marino et al., 2017) consists of 15 items (e.g., "I would feel lost if I was unable to access Facebook") rated on an 8-point scale from (1) "definitely disagree" to (8) "definitely agree." Scores across the items were averaged to provide a total score for PFU. Higher scores indicate higher levels of PFU. The PFUS has been showed to have good psychometric proprieties, with good internal consistency of the overall scale scores and invariance across age and gender groups (Marino et al., 2017). In this study, polychoric Cronbach's $\alpha$ s of the overall scale's scores were $.91[95 \% \mathrm{CI}=0.90-0.93]$ and $.94[95 \%$ $\mathrm{CI}=0.93-0.95]$ in Study 1 and Study 2, respectively.

Metacognitions. The MCQ-30 (Quattropani et al., 2014; Wells \& Cartwright-Hatton, 2004) consists of 30 items rated 


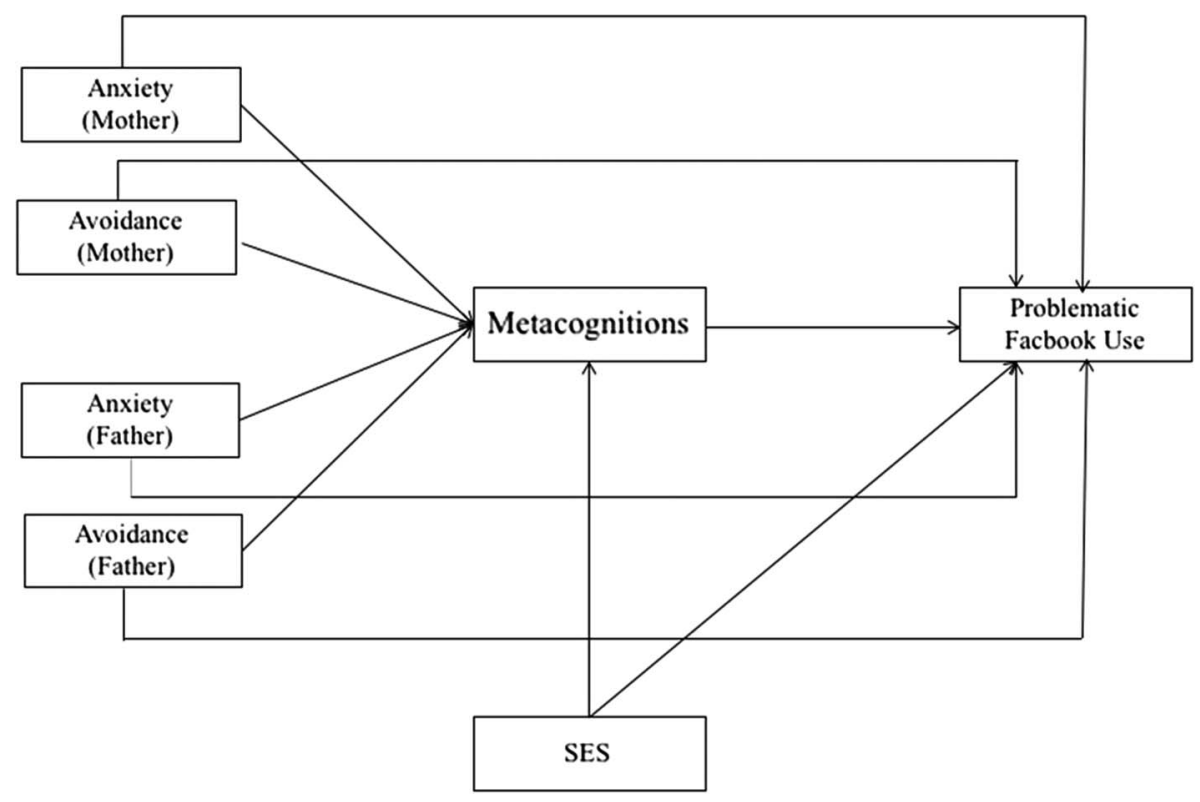

Figure 2. The theoretical model of problematic Facebook use developed for Study 2. Note. SES: socioeconomic status

on a 4-point scale from (1) "definitely disagree" to (4) "definitely agree." It consists of five factors assessed using six items each: (a) positive beliefs about worry (e.g. "Worrying helps me cope"), (b) negative beliefs about thoughts (e.g., "When I start worrying I cannot stop"), (c) lack of cognitive confidence (e.g., "My memory can mislead me at times"), (d) beliefs about the need to control thoughts (e.g., "Not being able to control my thoughts is a sign of weakness"), and (e) cognitive self-consciousness (e.g., "I pay close attention to the way my mind works"). For the purpose of this study and consistent with previous studies (e.g., Debbané, Van der Linden, Balanzin, Billieux, \& Eliez, 2012; Spada \& Marino, 2017; Spada, Mohiyeddini, \& Wells, 2008), a composite score composed of the first four subscales (24 items) was computed. Scores across the items were averaged to provide a total score. Higher scores indicate higher levels of maladaptive metacognitions. The polychoric Cronbach's $\alpha$ s computed on the 24 items were $.91[95 \% \mathrm{CI}=0.89-0.92]$ and .94 $[95 \% \mathrm{CI}=0.93-0.95]$ in Study 1 and Study 2, respectively.

\section{Statistical analysis}

First, bivariate Pearson's correlations were performed in order to evaluate the relationships among the variables of interest. In order to examine the pattern of relationships specified by our theoretical model, a path-analytic model approach (i.e., structural equation modeling for observed variables) was employed in both studies, using a single observed score for each construct included in the model. Specifically, in Study 1, the model included the six attachment dimensions [trust, communication, and alienation toward mother and father - independent variables (IVs)] and the metacognitions score as a mediator. The dependent variable (DV) was PFU. In Study 2, the model included anxiety and avoidance dimensions with respect to attachment with mother and father (IVs), and the metacognitions score as mediator. The DV was PFU. In both studies, all direct and indirect paths from the IVs to the DV were estimated. The SES was included in the models as covariates of metacognitions and PFU (Figures 1 and 2).

In order to select the most plausible model, we first tested the full model. Subsequently, we removed step-by-step path coefficients not significant at the 5\% level. Since several variables were non-normally distributed, path models were fitted using the robust maximum likelihood methods (Satorra \& Bentler, 1994). All models were tested using the Satorra-Bentler $\chi^{2}$ statistic, and the tests of significance of parameters were computed using robust standard errors.

The mediating role of metacognitions was evaluated using the Sobel tests for mediation, also known as the product of coefficients approach (Baron \& Kenny, 1986; Hayes, 2009). To evaluate the goodness of fit of the model, several indices of fit for structural equation models [i.e., $\chi^{2}$, comparative fit index (CFI), non-normed fit index (NNFI), and root mean square error of approximation (RMSEA)] were considered as well as the explained variance of each endogenous variable $\left(R^{2}\right)$ and the total coefficient of determination (TCD; Bollen, 1989; Jöreskog \& Sörbom, 1996).

Then, to test invariance across gender, a multigroup analysis was performed and the equality of path coefficients between boys and girls was tested. Specifically, a model in which all regression coefficients were constrained to be equal across groups was compared with the configural model in which parameters were allowed to vary (van de Schoot \& Strohmeier, 2011). The Wald $\chi^{2}$ tests were used to test the null hypothesis that the regression coefficients for the predictors of PFU were the same between girls and boys. A non-significant Wald test gives support for equality of regression coefficients between groups. Furthermore, the fit indices of the models [i.e., $\chi^{2}$, CFI, Tucker-Lewis index (TLI), RMSEA, and standardized root mean square residual (SRMR)] were considered and - at the qualitative level - we evaluated the differences of explained variance of each endogenous variable $\left(R^{2}\right)$. Following the same procedure, 
invariance across middle (14-16 years old) and late adolescents (17-20 years old) was tested.

Data analyses were run using the Lavaan package (Rosseel, 2012) of the software R (R Core Team, 2013).

\section{Ethics}

The current research received formal approval by the Ethics Committee for Psychological Research at the University of Padova, Italy. Permission for the studies was sought from the Head of School, and a letter was sent to students' parents in order to explain the nature of the study and ask for their consent. Signed consent was obtained from both parents, whereas students of age provided their own written consent. Moreover, verbal assent was obtained from participants before starting data collection.

\section{RESULTS}

Study 1

Table 1 shows the means, standard deviations, and bivariate correlations between the variables included in the study. PFU was found to be negatively correlated with trust and communication toward mother but not toward father, and positively correlated with alienation toward both mother and father. Moreover, PFU was positively correlated with metacognitions. The covariance matrix of the observed variables included in the full initial model tested in Study 1 is reported in Supplementary Table S1.

The first path model included all attachment-related dimensions (i.e., trust, communication, and alienation toward mother and father), PFU, and metacognitions. After having tested this model, we removed the following nonsignificant paths step-by-step: (a) the link between trust and alienation toward father and PFU, (b) the link between two attachment-related dimensions toward mother (i.e., trust and communication) and PFU, (c) the link between trust toward father and metacognitions, and (d) the link between communication and trust toward mother and metacognitions. Five significant paths remained in the best fitting model: (a) the link between two father's attachment-related dimensions (i.e., disaffection and communication) and metacognitions, (b) alienation toward mother's and metacognitions, (c) the link between alienation toward mother's and PFU, and (d) the link between metacognitions and PFU. SES was maintained as fixed covariate.

The resulting path model (Figure 3) reported a good fit $\left[\chi^{2} / d f=0.763, \mathrm{CFI}=1.000, \mathrm{TLI}=1.025, \mathrm{SRMR}=0.008\right.$, RMSEA $=0.000(0.000-0.108)]$. In this model, indirect paths by metacognitions from the IVs (i.e., alienation toward mother and father and communication with father) to the DV (PFU) were included. The results of three separate Sobel tests supported a mediating role of metacognitions in links between mother alienation $(\beta=0.053, S E=0.022$, $z=2.446, p=.014)$ and father alienation and PFU $(\beta=$ $0.097, S E=0.028, z=3.309, p=.001)$ as well father communication $(\beta=0.049, S E=0.019, z=2.236, p=.025)$ and PFU. The $R^{2}$ for the endogenous variables indicates that the 


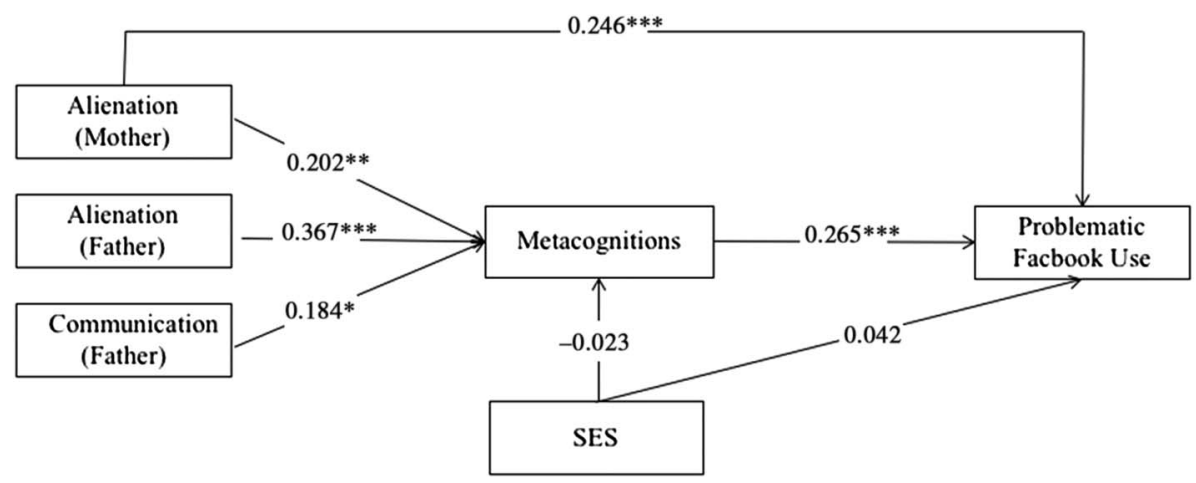

Figure 3. The final model of problematic Facebook use (Study 1), showing the interrelationships between the variables. Note. ${ }^{*} p<.05$. $* * p<.01 . * * * p<.001 . N=271$

model accounts for $17.5 \%$ of the variance for the outcome variable (PFU) and $17.6 \%$ of the variance for the mediator (metacognitive beliefs). Overall, the total amount of variance explained by the model $(\mathrm{TCD}=0.23)$ indicated a satisfactory fit to the observed data.

The multigroup analyses were then performed. The configural model across gender showed good fit $\left[\chi^{2} / d f=1.66\right.$, $\mathrm{CFI}=0.976, \quad \mathrm{TLI}=0.890, \quad \mathrm{SRMR}=0.017, \quad \mathrm{RMSEA}=$ $0.067(0.000-0.161)]$. Similarly, the model in which all regression coefficients were constrained to be equal across groups $\left[\chi^{2} / d f=1.07, \mathrm{CFI}=0.996, \mathrm{TLI}=0.998, \mathrm{SRMR}=\right.$ 0.018$, RMSEA $=0.022(0.000-0.113)]$ yielded good fit and the results from the omnibus Wald $\chi^{2}$ tests supported invariance across gender [Wald $\chi^{2}(2)=0.133, p=.936$ ]. The $R^{2}$ for the endogenous variables indicated that the model accounts for $18.1 \%$ and $16.9 \%$ of the variance for the outcome variable (PFU) and $18.2 \%$ and $17.5 \%$ of the variance for the mediator (metacognitions), respectively, in boys and girls.

With regard to age, the configural model showed good fit $\left[\chi^{2} / d f=0.65825, \mathrm{CFI}=1.000, \mathrm{TLI}=1.059, \mathrm{SRMR}=\right.$ 0.011$, RMSEA $=0.000(0.000-0.105)]$ as well as the restricted model $\left[\chi^{2} / d f=0.828, \mathrm{CFI}=1.000, \mathrm{TLI}=1.030\right.$, $\mathrm{SRMR}=0.019$, RMSEA $=0.000(0.000-0.098)]$. Invariance across middle and late adolescents was supported [Wald $\left.\chi^{2}(30)=29.07, p=0.41\right)$ ] suggesting the equality of regression coefficients across groups. The $R^{2}$ for the endogenous variables indicated that the model accounts for $22 \%$ and $17.3 \%$ of the variance for the outcome variable (PFU), and $21.8 \%$ and $15.9 \%$ of the variance for the mediator (metacognitions), respectively, in middle and late adolescents. The standardized regression coefficients are reported in the "Appendix" section (Figures A1 and A2).

To sum up, the findings from the test for invariance support the equality of regression coefficients across gender and age groups. However, caution should be used given the different significant level yield in path coefficients which may in part reflect the low and different sample size (i.e., girls: $n=184$; boys: $n=87$ ) and the low statistical power.

\section{Study 2}

Table 2 shows the means, standard deviations, and bivariate correlations between the variables included in the study. PFU was found to be positively correlated with anxiety toward mother and father. Moreover, PFU use was positively correlated with metacognitions. The covariance matrix of the observed variables included in the full initial model tested in Study 2 is reported in Supplementary Table S2.

The first path model included anxiety and avoidant toward parents (IVs), PFU (DV), and metacognitions as mediator (Figure 3). Several path coefficients did not reach statistical significance at the 5\% level and thus have been removed: (a) the link between father's attachment-related dimensions (i.e., anxiety and avoidance), mother's avoidance, and PFU; (b) the link between father's avoidance and metacognitions. Four significant paths remained in the best fitting model: (a) the link between anxiety toward both

Table 2. Means, standard deviations (SDs), and Pearson's correlations of observed variables of Study 2

\begin{tabular}{|c|c|c|c|c|c|c|c|c|c|c|c|c|}
\hline & & Mean & $S D$ & (1) & (2) & (3) & (4) & (5) & (6) & (7) & (8) & (9) \\
\hline (1) & Gender & & & - & & & & & & & & \\
\hline (2) & Age & 16.22 & 1.41 & -.25 & - & & & & & & & \\
\hline (3) & SES & 6.39 & 1.69 & -.16 & .10 & - & & & & & & \\
\hline (4) & $\begin{array}{l}\text { Problematic } \\
\text { Facebook use }\end{array}$ & 1.74 & 0.82 & .07 & -.04 & -.03 & - & & & & & \\
\hline (5) & Anxiety (mother) & 1.62 & 1.16 & .06 & -.09 & -.05 & $.33^{* * *}$ & - & & & & \\
\hline (6) & Avoidance (mother) & 3.43 & 1.68 & -.16 & -.02 & -.08 & .08 & $.26^{* * *}$ & - & & & \\
\hline (7) & Anxiety (father) & 1.74 & 1.41 & .09 & $-.14 *$ & -.07 & $.25^{* * *}$ & $.64 * * *$ & $.18^{* *}$ & - & & \\
\hline (8) & Avoidance (father) & 3.89 & 1.62 & .07 & -.02 & $-.13^{*}$ & .03 & $.16^{* *}$ & $.50^{* * *}$ & $.38 * * *$ & - & \\
\hline (9) & Metacognitions & 2.05 & 0.51 & .14 & -.06 & -.06 & $.31 * * *$ & $.33 * * *$ & $.24 * * *$ & $.33 * * *$ & $.16^{* *}$ & - \\
\hline
\end{tabular}

Note. $N=336$; Gender code: $1=$ male, $2=$ female. SES: socioeconomic status.

$*_{p}<.05 . * * p<.01 . * * * p<.001$. 


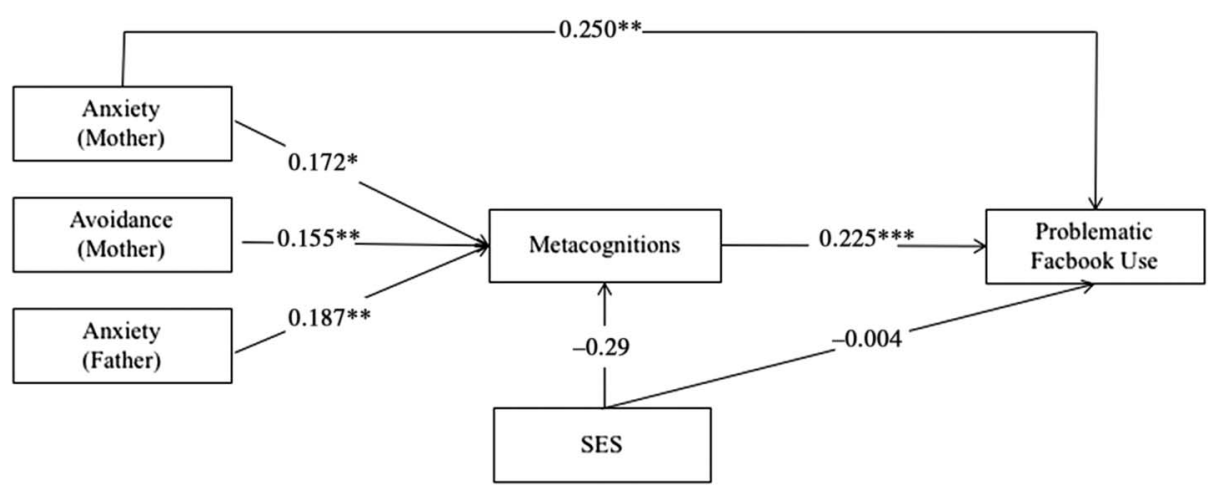

Figure 4. The final model of problematic Facebook use (Study 2), showing the interrelationships between the variables. Note. ${ }^{*} p<.05$.

$$
* * p<.01 . * * * p<.001 . N=336
$$

mother and father and metacognitions, (b) avoidance toward mother's and metacognitions, (c) the link between anxiety toward mother and PFU, and (d) the link between metacognitions and PFU. In this model, indirect paths by metacognitions from the IVs (i.e., attachment relateddimensions) to the DV (i.e., PFU) were included. In the final model (Figure 4), with the exception of the path between covariates (i.e., age and gender) and metacognitions, all path coefficients were statistically significant at the $5 \%$. Moreover, fit indices showed a good fit of the model $\left[\chi^{2} / d f=0.428\right.$, $\mathrm{CFI}=1.00, \mathrm{TLI}=1.077, \mathrm{SRMR}=0.009, \mathrm{RMSEA}=0.000$ (0.000-0.056)].

The results of the Sobel test supported the mediating role of metacognitions in the link between avoidance toward mother and PFU $(\beta=0.035, S E=0.007, z=2.355, p=.019)$. The mediation role of metacognitions was also supported in the link between anxiety toward father and PFU $(\beta=0.042$, $S E=0.012, z=2.075, p=.038)$. Furthermore, the mediation role of metacognitions was close to the statistical significance in links between anxiety toward mother and PFU $(\beta=0.039$, $S E=0.014, z=1.879, p=.060$ ).

The $R^{2}$ for the endogenous variables indicates that the model accounts for $15.1 \%$ of the variance for the outcome variable (PFU) and for $15.7 \%$ of the variance for the mediator (metacognitions). Overall, the total amount of variance explained by the model $(\mathrm{TDC}=0.21)$ indicated a satisfactory fit to the observed data.

The multigroup analyses were then performed. The configural model across gender (see Figure A3 in the "Appendix" section) showed good fit $\left[\chi^{2} / d f=1.013, \quad \mathrm{CFI}=0.999\right.$, $\mathrm{TLI}=0.997, \mathrm{SRMR}=0.017, \mathrm{RMSEA}=0.009(0.000-0.112)]$ and a decrease of all fit indexes in the constrained model $\left[\chi^{2} / d f=2.00, \quad\right.$ CFI $=0.938, \quad$ TLI $=0.813, \quad$ SRMR $=0.035$, RMSEA $=0.077(0.000-0.139)]$. The results from the Wald $\chi^{2}$ tests did not support invariance across gender [Wald $\left.\chi^{2}(2)=8.888, p=.012\right]$. The results of Sobel test supported the mediating role of metacognitions in the link between avoidance toward mother and PFU in boys $(\beta=0.054$, $S E=0.013, z=2.038, p=.042$ ), but no other significant mediating effects emerged. The $R^{2}$ for the endogenous variables indicates that the model accounts for $15.9 \%$ and $14.4 \%$ of the variance for the outcome variable (PFU) and $17.3 \%$ and $16.1 \%$ of the variance for the mediator (metacognitive beliefs), respectively, in boys and girls.
With age, the configural models (see Figure A4 in the "Appendix" section) showed good fit in both unconstrained $\left[\chi^{2} / d f=1.00, \quad \mathrm{CFI}=1.00, \quad \mathrm{TLI}=1.00, \quad \mathrm{SRMR}=0.016\right.$, RMSEA $=0.000(0.000-0.112)]$ and constrained models $\left[\chi^{2} / d f=2.00, \mathrm{CFI}=0.985, \mathrm{TLI}=0.956, \quad \mathrm{SRMR}=0.024\right.$, $\mathrm{RMSEA}=0.039(0.000-0.112)]$, and invariance across middle and late adolescents was supported [Wald $\chi^{2}(2)=$ $3.87, p=.45]$ suggesting the equality of regression coefficients across groups.

In conclusion, the equality of regression coefficients was supported between middle and late adolescents but not between boys and girls. Similarly to Study 1, caution should be given to generalize these results and replication with larger samples. Moreover, considering simultaneously the potential moderation effect of age and gender is recommended in future studies.

\section{DISCUSSION AND CONCLUSIONS}

The goal of these studies was to investigate the association between attachment styles, metacognitions, and PFU among adolescents. Overall, the findings underscore the relative importance of different attachment dimensions in predicting PFU and the mediating role of metacognitions between attachment dimensions and PFU.

The results from Study 1 and Study 2 seem to partially support the first hypothesis. Bivariate associations suggest that security dimensions are linked to PFU with the exception of communication with father (Study 1; Table 1). With regard to insecurity, correlations show that anxiety (mother and father), but not avoidance, is linked to PFU (Study 2; Table 2). Interestingly, when testing the path models (see Figures 2 and 3), only two distinct dimensions, both related to mother, are still directly linked to PFU, indicating the importance to understand the potential underlying psychological mechanism. Specifically, the links between alienation (mother; from Study 1) and anxiety (mother; from Study 2) seem to directly influence PFU. These results support the idea that less secure adolescents experiencing feelings of isolation or anger toward an unresponsive mother (alienation) are more likely to engage in PFU (Lei \& Wu, 2007), for example, preferring online social interactions on social media rather than face-to-face ones and regulating 
their mood on Facebook (Assunção \& Matos, 2017). Similarly, Facebook use may offer advantages over offline interactions for individuals with insecure attachment (anxiety), for example, by offering the possibility to manage self-presentation and time and space of interaction (Hart et al., 2015). It has been indeed advocated that those with high levels of anxiety in attachment relationships may use Facebook more consistently because of their need to receive continuous feedback in the form of "likes" and comments (Oldmeadow et al., 2013), whereas avoidant individuals may feel less comfortable in online interaction and show limited Facebook use because of their need to avoid interpersonal intimacy (Hart et al., 2015). Contrary to our expectations, attachment with father does not appear to influence PFU directly. However, this may in part support the hypotheses that the quality of attachment with father and mother is involved in different domains of adolescents' social adjustment with fathers playing a prominent role in teaching skills for conflict resolution, thus preventing problematic behaviors (Lieberman, Doyle, \& Markiewicz, 1999).

With respect to the second hypothesis, the direct link found in both Study 1 and Study 2 between metacognitions and PFU expands the small but growing evidence base on the association between metacognitions and problematic online behaviors, like PFU. Indeed, the results support the hypothesis showing that maladaptive thinking styles may be involved in worsening the levels of PFU among adolescents. Specifically, metacognitions are believed to activate maladaptive coping strategies to cope with thoughts and internal events, which in turn may lead to Internet and Facebook use as a means of self-regulation (Marino et al., 2016; Spada \& Marino, 2017). These findings are indeed in line with previous studies demonstrating such role of metacognitions among adult Facebook users and adolescent Internet users in general (Marino et al., 2016; Spada \& Marino, 2017).

Regarding the third hypothesis, the results show that metacognitions mediate the relationship between certain attachment dimensions and PFU. Specifically, low levels of secure attachment and high levels of insecure attachment may be responsible for the activation and perseverance of maladaptive cognitive and emotional regulation strategies, which in turn lead to negative symptoms (Myers \& Wells, 2015), including PFU (Marino et al., 2018a). An interesting result is the positive link between communication with father and metacognitions: it seems that talking with father about problems and worries led adolescents to engage in maladaptive cognitive strategies like perseverative thinking (Balsamo \& Carlucci, 2016) and thus in PFU. A possible explanation for this result can be viewed in light of theories about co-rumination (Rose, 2002): on one hand, communicating with father led to experience closeness and support in father-adolescent relationship (Lei \& Wu, 2007); on the other hand, discussing problems in an excessive and repetitive way may led to impairments of psychological functioning among adolescents (Hart \& Thompson, 1997) and, in turn, to PFU (Lei \& Wu, 2007). However, the role of attachment with father in PFU and PIU is understudied (Lei \& Wu, 2007) and future studies should shed light on those associations.

With regard to insecurity, attachment anxiety (mother and father) and avoidance (mother) are positively linked to metacognitions and in turn to PFU. It is likely that anxiety may guide children toward threat monitoring, and focusing attention on signals of separation and danger, as well as to engage in cognitive processes like rumination (Malik, Wells, \& Wittkowski, 2015). From this perspective, anxious children should be more likely to develop both positive metacognitions about the usefulness of perseverative thinking and negative beliefs about thought uncontrollability and danger (Caselli et al., 2017). Conversely, children with high levels of attachment avoidance should be more prone to engage in thought suppression (natural threat repressing), and focus their attention on denying the need for closeness. Moreover, in terms of metacognitive knowledge, avoidant styles may guide children to believe that thoughts and emotions are dangerous and uncontrollable, and thus to perceive the need to control thoughts (Caselli et al., 2017; Moss, Erskine, Albery, Allen, \& Georgiou, 2015). In both cases, the activation of maladaptive metacognitions seems to be associated with higher levels of PFU (Marino et al., 2016).

In conclusion, since attachment styles and PFU may significantly affect adolescents' development and wellbeing (Allen, Moore, Kuperminc, \& Bell, 1998), the results of this study may provide some practical indications for researchers and practitioners implementing prevention programs for adolescents. For example, interventions tackling PFU could try to modify adolescents' thinking styles, for example, in terms of positive and negative metacognitions, while also taking into account different attachment styles (Marino et al., 2016). Moreover, prevention of PFU could improve emotional skills, attitudes, and behaviors following the social and emotional learning approach, which has been recognized as highly effective among adolescents (Durlak, Weissberg, Dymnicki, Taylor, \& Schellinger, 2011). Furthermore, parent education is recommended in order to make adults aware of the meaning of social media for their children as well as being able to recognize problematic use of technology when it arises (Willard, 2012).

Although our research provides conceptual insights of the relationships among attachment representations, metacognitions, and PFU, some limitations should be noted, and further studies are needed. First, the cross-sectional design may only be suggestive of the mechanisms linking attachment styles to PFU through metacognitions. Second, these studies are also limited by the use of self-report questionnaires. Alternative measures of attachment representation (e.g., interview) should be applied to gain a more nuanced picture of the association between attachment styles and PFU in middle and late adolescence. Third, future studies should also examine the role of attachment to peers and significant others beyond attachment with parents. Moreover, the limited sample sizes of each study hampers the possibility to generalize findings and future studies should understand more in-depth the association between different types of attachment styles and metacognitions. Specifically, replications with larger samples as well as considering simultaneously the potential moderating effects of age and gender are warranted in order to address the generalizability issue. Finally, this study is based on an Italian context. Thus, further studies should replicate this study in other countries and across different cultures. Moreover, future studies should 
explore the contribution of other individual characteristics (such as temperament and personality) in influencing the effect of attachment on problematic social media use.

Despite these limitations, the current studies highlight not only the relative influence of different attachment styles on PFU, but also the importance of metacognitions in mediating such relationship in adolescents.

Funding sources: No financial support was received for this study.

Authors' contribution: CM, MMS, and GC are responsible for the study concept and design. CM wrote the first draft. TM performed analysis. GA supervised the statistical analysis and contributed to the interpretation of data. LF was involved in review of literature and data collection. MMS, AV, and AS performed study supervision. AS and GC contributed to the interpretation of data and critical revision.

Conflict of interest: The authors declare no conflict of interest.

\section{REFERENCES}

Akbari, M. (2017). Metacognitions or distress intolerance: The mediating role in the relationship between emotional dysregulation and problematic Internet use. Addictive Behaviors Reports, 6, 128-133. doi:10.1016/j.abrep.2017.10.004

Allen, J. P., McElhaney, K. B., Land, D. J., Kuperminc, G. P., Moore, C. W., O'Beirne-Kelly, H., \& Kilmer, S. L. (2003). A secure base in adolescence: Markers of attachment security in the mother-adolescent relationship. Child Development, 74(1), 292-307. doi:10.1111/1467-8624.t01-1-00536

Allen, J. P., Moore, C., Kuperminc, G., \& Bell, K. (1998). Attachment and adolescent psychosocial functioning. Child Development, 69(5), 1406-1419. doi:10.2307/1132274

Andreassen, C. S., \& Pallesen, S. (2014). Social network site addiction: An overview. Current Pharmaceutical Design, 20(25), 4053-4061. doi:10.2174/13816128113199990616

Andreassen, C. S., Pallesen, S., \& Griffiths, M. D. (2017). The relationship between addictive use of social media, narcissism, and self-esteem: Findings from a large national survey. Addictive Behaviors, 64, 287-293. doi:10.1016/j.addbeh.2016. 03.006

Armsden, G. C., \& Greenberg, M. T. (1989). Inventory of Parent and Peer Attachment (IPPA). Seattle, WA: University of Washington.

Arpaci, I., Baloolu, M., Kozan, H. I. O., \& Kesici, S. (2017). Individual differences in the relationship between attachment and nomophobia among college students: The mediating role of mindfulness. Journal of Medical Internet Research, 19(12), e404. doi:10.2196/jmir. 8847

Assunção, R., \& Matos, P. M. (2017). Adolescents' profiles of problematic Facebook use and associations with developmental variables. Computers in Human Behavior, 75, 396-403. doi:10.1016/j.chb.2017.05.034
Balsamo, M., \& Carlucci, L. (2016). Validazione della versione italiana del Co-Rumination Questionnaire: Risultati preliminari [Validation of the Italian version of the CoRumination Questionnaire: Preliminary results]. Psicoterapia Cognitiva e Comportamentale, 22(1), 13-34.

Baron, R. M., \& Kenny, D. A. (1986). The moderator-mediator variable distinction in social psychological research: Conceptual, strategic, and statistical considerations. Journal of Personality and Social Psychology, 51(6), 1173-1182. doi:10.1037/0022-3514.51.6.1173

Baturay, M. H., \& Toker, S. (2017). Self-esteem shapes the impact of GPA and general health on Facebook addiction: A mediation analysis. Social Science Computer Review, 35(5), 555-575. doi:10.1177/0894439316656606

Biolcati, R., Mancini, G., Pupi, V., \& Mugheddu, V. (2018). Facebook addiction: Onset predictors. Journal of Clinical Medicine, 7(6), 118. doi:10.3390/jcm7060118

Bollen, K. A. (1989). Structural equations with latent variables. New York, NY: Wiley.

Bowlby, J. (1969). Attachment and loss. Volume 1: Attachment. New York, NY: Basic Books.

Boyce, W., Torsheim, T., Currie, C., \& Zambon, A. (2006). The Family Affluence Scale as a measure of national wealth: Validation of an adolescent self-report measure. Social Indicators Research, 78(3), 473-487. doi:10.1007/s11205005-1607-6

Brennan, K. A., Clark, C. L., \& Shaver, P. R. (1998). Self-report measures of adult attachment. In J. Simpson \& W. Rholes (Eds.), Attachment theory and close relationships (pp. 46-76). New York, NY: Guildford Press.

Brenning, K., Soenens, B., Braet, C., \& Bosmans, G. (2011). An adaptation of the Experiences in Close Relationships Scale - Revised for Use with Children and Adolescents. Journal of Social and Personal Relationships, 28(8), 1048-1072. doi:10.1177/0265407511402418

Brenning, K. M., Soenens, B., Braet, C., \& Bosmans, G. (2012). Attachment and depressive symptoms in middle childhood and early adolescence: Testing the validity of the emotion regulation model of attachment. Personal Relationships, 19(3), 445-464. doi:10.1111/j.1475-6811.2011.01372.x

Brenning, K., Van Petegem, S., Vanhalst, J., \& Soenens, B. (2014). The psychometric qualities of a short version of the Experiences in Close Relationships Scale - Revised Child version. Personality and Individual Differences, 68, 118-123. doi:10.1016/j.paid.2014.04.005

Caplan, S. (2010). Theory and measurement of generalized problematic Internet use: A two-step approach. Computers in Human Behavior, 26(5), 1089-1097. doi:10.1016/j.chb. 2010.03.012

Casale, S., Caplan, S. E., \& Fioravanti, G. (2016). Positive metacognitions about Internet use: The mediating role in the relationship between emotional dysregulation and problematic use. Addictive Behaviors, 59, 84-88. doi:10.1016/j.addbeh. 2016.03.014

Caselli, G., Ruggiero, G. M., \& Sassaroli, S. (2017). Rimuginio. Teoria e terapia del pensiero ripetitivo [Worry. Theory and therapy of repetitive thinking]. Milano, Italy: Raffaello Cortina Editore.

Debbané, M., Van der Linden, M., Balanzin, D., Billieux, J., \& Eliez, S. (2012). Associations among metacognitive beliefs, anxiety and positive schizotypy during adolescence. 
The Journal of Nervous and Mental Disease, 200(7), 620-626. doi:10.1097/NMD.0b013e31825bfc1a

Durlak, J. A., Weissberg, R. P., Dymnicki, A. B., Taylor, R. D., \& Schellinger, K. B. (2011). The impact of enhancing students' social and emotional learning: A meta-analysis of school-based universal interventions. Child Development, 82(1), 405-432. doi:10.1111/j.1467-8624.2010.01564.x

Esbjørn, B. H., Bender, P. K., Reinholdt-Dunne, M. L., Munck, L. A., \& Ollendick, T. H. (2012). The development of anxiety disorders: Considering the contributions of attachment and emotion regulation. Clinical Child and Family Psychology Review, 15(2), 129-143. doi:10.1007/s10567-011-0105-4

Fox, J., \& Moreland, J. J. (2015). The dark side of social networking sites: An exploration of the relational and psychological stressors associated with Facebook use and affordances. Computers in Human Behavior, 45, 168-176. doi:10.1016/j.chb.2014.11.083

Fox, J., Osborn, J., \& Warber, K. (2014). Relational dialectics and social networking sites: The role of Facebook in romantic relationship escalation, maintenance, conflict, and dissolution. Computers in Human Behavior, 35, 527-534. doi:10.1016/ j.chb.2014.02.031

Fraley, R. C., Waller, N. G., \& Brennan, K. A. (2000). An item response theory analysis of self-report measures of adult attachment. Journal of Personality and Social Psychology, 78(2), 350-365. doi:10.1037//0022-3514.78.2.350

Gil de Zúñiga, H., Jung, N., \& Valenzuela, S. (2012). Social media use for news and individuals' social capital, civic engagement and political participation. Journal of Computer-Mediated Communication, 17(3), 319-336. doi:10.1111/j.1083-6101. 2012.01574.x

Gil de Zúñiga, H., Molyneux, L., \& Zheng, P. (2014). Social media, political expression and political participation: Panel analysis of lagged and concurrent relationships. Journal of Communication, 64(4), 612-634. doi:10.1111/jcom.12103

Griffiths, M. D., Kuss, D. J., \& Demetrovics, Z. (2014). Social networking addiction: An overview of preliminary findings. In K. P. Rosenberg \& L. C. Feder (Eds.), Behavioral addictions. Criteria, evidence, and treatment (pp. 119-141). New York, NY: Elsevier.

Guarnieri, S., Ponti, L., \& Tani, F. (2010). The Inventory of Parent and Peer Attachment (IPPA): A study on the validity of styles of adolescent attachment to parents and peers in an Italian sample. TPM-Testing, Psychometrics, Methodology in Applied Psychology, 17(3), 103-130.

Hart, B. I., \& Thompson, J. T. (1997). Gender role characteristics and depressive symptomatology among adolescents. Journal of Early Adolescence, 16(4), 407-426. doi:10.1177/ 0272431696016004003

Hart, J., Nailling, E., Bizer, G. Y., \& Collins, C. K. (2015). Attachment theory as a framework for explaining engagement with Facebook. Personality and Individual Differences, 77, 33-40. doi:10.1016/j.paid.2014.12.016

Hayes, A. F. (2009). Beyond Baron and Kenny: Statistical mediation analysis in the new millennium. Communication Monographs, 76(4), 408-420. doi:10.1080/03637750903310360

Huang, C. (2018). Social network site use and academic achievement: A meta-analysis. Computers \& Education, 119, 76-83. doi:10.1016/j.compedu.2017.12.010

Jenkins-Guarnieri, M. A., Wright, S. L., \& Hudiburgh, L. M. (2012). The relationships among attachment style, personality traits, interpersonal competency, and Facebook use. Journal of Applied Developmental Psychology, 33(6), 294-301. doi:10.1016/j.appdev.2012.08.001

Jenkins-Guarnieri, M. A., Wright, S. L., \& Johnson, B. (2013). Development and validation of a Social Media Use Integration Scale. Psychology of Popular Media Culture, 2(1), 38-50. doi:10.1037/a0030277

Jöreskog, K. G., \& Sörbom, D. (1996). LISREL 8: User's reference guide. Chicago, IL: Scientific Software International.

Kalaitzaki, A. E., \& Birtchnell, J. (2014). The impact of early parenting bonding on young adults' Internet addiction, through the mediation effects of negative relating toothers and sadness. Addictive Behavior, 39(3), 733-736. doi:10.1016/j.addbeh. 2013.12.002

Kerns, K. A., \& Brumariu, L. E. (2016). Attachment in middle childhood. In J. Cassidy \& P. Shaver (Eds.), Handbook of attachment (pp. 349-365). New York, NY: Guilford Press.

Kerns, K. A., Schlegelmilch, A., Morgan, T. A., \& Abraham, M. M. (2005). Assessing attachment in middle childhood. In K. A. Kerns \& R. A. Richardson (Eds.), Attachment in middle childhood (pp. 46-70). New York, NY: Guilford Press.

Kuss, D. J., \& Griffiths, M. D. (2011). Online social networking and addiction - A review of the psychological literature. International Journal of Environmental Research and Public Health, 8(9), 3528-3552. doi:10.3390/ijerph8093528

LaRose, R., Lin, C. A., \& Eastin, M. S. (2003). Unregulated Internet usage: Addiction, habit, or deficient self-regulation? Media Psychology, 5(3), 225-253. doi:10.1207/S153278 5XMEP0503_01

Lee, Z., Cheung, C. K., \& Thadani, D. R. (2012). An investigation into the problematic use of Facebook. Paper presented at 45th Hawaii International Conference on System Sciences, Maui, HI.

Lei, L., \& Wu, Y. (2007). Adolescents' paternal attachment and Internet use. CyberPsychology \& Behavior, 10(5), 633-639. doi:10.1089/cpb.2007.9976

Lenzi, M., Vieno, A., Altoè, G., Scacchi, L., Perkins, D. D., Zukauskiene, R., \& Santinello, M. (2015). Can Facebook informational use foster adolescent civic engagement? American Journal of Community Psychology, 55(3-4), 444-454. doi:10.1007/s10464-015-9723-1

Lieberman, M., Doyle, A., \& Markiewicz, D. (1999). Developmental patterns in security of attachment to mother and father in late childhood and early adolescence: Associations with peer relations. Child Development, 70(1), 202-213. doi:10.1111/ 1467-8624.00015

Lin, J. H. (2015). The role of attachment style in Facebook use and social capital: Evidence from university students and a national sample. Cyberpsychology, Behavior, and Social Networking, 18(3), 173-180. doi:10.1089/cyber.2014.0341

Liu, C., \& Kuo, F. (2007). A study of Internet addiction through the lens of the interpersonal theory. CyberPsychology \& Behavior, 10(6), 799-804. doi:10.1089/cpb.2007.9951

Liu, D., Kirschner, P. A., \& Karpinski, A. C. (2017). A meta-analysis of the relationship of academic performance and social network site use among adolescents and young adults. Computers in Human Behavior, 77, 148-157. doi:10.1016/j.chb.2017.08.039

Lynch, M., \& Cicchetti, D. (1997). Children's relationships with adult and peers: An examination of elementary and junior high school students. Journal of School Psychology, 35(1), 81-99. doi:10.1016/S0022-4405(96)00031-3 
Malik, S., \& Khan, M. (2015). Impact of Facebook addiction on narcissistic behavior and self-esteem among students. Journal of the Pakistan Medical Association, 65(3), 260-263.

Malik, S., Wells, A., \& Wittkowski, A. (2015). Emotion regulation as a mediator in the relationship between attachment and depressive symptomatology: A systematic review. Journal of Affective Disorders, 172, 428-444. doi:10.1016/j.jad.2014. 10.007

Mansueto, G., Pennelli, M., De Palo, V., Monacis, L., Sinatra, M., \& De Caro, M. F. (2016). The role of metacognition in pathological gambling: A mediation model. Journal of Gambling Studies, 32(1), 93-106. doi:10.1007/s10899-0149519-5

Marci, T., Moscardino, U., \& Altoé, G. (2018). The Brief Experience in Close Relationships Scale - Revised child version (ECR-RC): Factor structure and invariance across middle childhood and early adolescence. International Journal of Behavioral Development. Advance online publication. 1-15. doi: $10.1177 / 0165025418785975$

Marino, C., Gini, G., Vieno, A., \& Spada, M. M. (2018a). The associations between problematic Facebook use, psychological distress and well-being among adolescents and young adults: A systematic review and meta-analysis. Journal of Affective Disorders, 226(226), 274-281. doi:10.1016/j.jad.2017.10.007

Marino, C., Gini, G., Vieno, A., \& Spada, M. M. (2018b). A comprehensive meta-analysis on problematic Facebook use. Computers in Human Behavior, 83, 262-277. doi:10.1016/ j.chb.2018.02.009

Marino, C., Vieno, A., Altoè, G., \& Spada, M. M. (2017). Factorial validity of the Problematic Facebook Use Scale for adolescents and young adults. Journal of Behavioral Addictions, 6(1), 5-10. doi:10.1556/2006.6.2017.004

Marino, C., Vieno, A., Moss, A. C., Caselli, G., Nikčević, A. V., \& Spada, M. M. (2016). Personality, motives and metacognitions as predictors of problematic Facebook use in university students. Personality and Individual Differences, 101, 70-77. doi:10.1016/j.paid.2016.05.053

Mayseless, O. (2005). Ontogeny of attachment in middle childhood: Conceptualization of normative changes. In K. A. Kerns \& R. A. Richardson (Eds.), Attachment in middle childhood (pp. 1-23). New York, NY: Guilford Press.

Mikulincer, M., \& Shaver, P. R. (2012). An attachment perspective on psychopathology. World Psychiatry, 11(1), 11-15. doi:10.1016/j.wpsyc.2012.01.003

Monacis, L., de Palo, V., Griffiths, M., \& Sinatra, M. (2017a). Social networking addiction, attachment style, and validation of the Italian version of the Bergen Social Media Addiction Scale. Journal of Behavioral Addictions, 6(2), 178-186. doi:10.1556/2006.6.2017.023

Monacis, L., de Palo, V., Griffiths, M. D., \& Sinatra, M. (2017b). Exploring individual differences in online addictions: The role of identity and attachment. International Journal of Mental Health and Addiction, 15(4), 853-868. doi:10.1007/s11469017-9768-5

Moreau, A., Laconi, S., Delfour, M., \& Chabrol, H. (2015). Psychopathological profiles of adolescent and young adult problematic Facebook users. Computers in Human Behavior, 44, 64-69. doi:10.1016/j.chb.2014.11.045

Moss, A. C., Erskine, J. A., Albery, I. P., Allen, J. R., \& Georgiou, G. J. (2015). To suppress, or not to suppress? That is repression: Controlling intrusive thoughts in addictive behaviour.
Addictive Behaviors, 44, 65-70. doi:10.1016/j.addbeh.2015. 01.029

Myers, S. G., \& Wells, A. (2015). Early trauma, negative affect, and anxious attachment: The role of metacognition. Anxiety, Stress, \& Coping, 28(6), 634-649. doi:10.1080/ 10615806.2015.1009832

Oldmeadow, J., Quinn, S., \& Kowert, R. (2013). Attachment style, social skills, and Facebook use amongst adults. Computers in Human Behavior, 29(3), 1142-1149. doi:10.1016/ j.chb.2012.10.006

Quattropani, M. C., Lenzo, V., Mucciardi, M., \& Toffle, M. E. (2014). Psychometric properties of the Italian version of the short form of the Metacognitions Questionnaire (MCQ-30). Bollettino di Psicologia Applicata, 269, 29-41. Retrieved from https://www.researchgate.net/publication/271469030_Psycho metric_properties_of_the_Italian_version_of_the_Short_Form of_the_Metacognitions_Questionnaire_MCQ-30

R Core Team. (2013). R: A language and environment for statistical computing [Computer software manual]. Vienna, Austria: R Foundation for Statistical Computing. Retrieved from http:// www.R-project.org/

Ryan, R. M., \& Lynch, J. H. (1989). Emotional autonomy versus detachment: Revisiting the vicissitudes of adolescence and young adulthood. Child Development, 60(2), 340-356. doi:10.2307/1130981

Rose, A. J. (2002). Co-rumination in the friendships of girls and boys. Child Development, 73(6), 1830-1843. doi:10.1111/ 1467-8624.00509

Rosseel, Y. (2012). Lavaan: An R package for structural equation modeling. Journal of Statistical Software, 48(2), 1-36. doi:10.18637/jss.v048.i02

San Martini, P., Zavattini, G. C., \& Ronconi, S. (2009). L'inventario per l'attaccamento ai genitori e ai pari (IPPA: Inventory of Parent and Peer Attachment). Un'indagine psicometrica su un campione Italiano di adolescent [The Inventory of Parent and Peer Attachment (IPPA). A psychometric investigation in a sample of Italian adolescents]. Giornale Italiano di Psicologia, 1, 199-225. doi:10.1421/29288

Satorra, A., \& Bentler, P. M. (1994). Corrections to test statistics and standard errors in covariance structure analysis. In A. Von Eye \& C. C. Clogg (Eds.), Latent variable analysis. Applications for developmental research (pp. 399-419). Thousand Oaks, CA: Sage.

Savc1, M., \& Aysan, F. (2016). The role of attachment styles, peer relations, and affections in predicting Internet addiction. Addicta: The Turkish Journal on Addictions, 3, 401-432. doi:10.15805/addicta.2016.3.0028

Schimmenti, A., Passanisi, A., Gervasi, A. M., Manzella, S., \& Famà, F. I. (2014). Insecure attachment attitudes in the onset of problematic Internet use among late adolescents. Child Psychiatry and Human Development, 45(5), 588-595. doi:10.1007/s10578-013-0428-0

Seabrook, E. M., Kern, M. L., \& Rickard, N. S. (2016). Social networking sites, depression, and anxiety: A systematic review. JMIR Mental Health, 3(4), e50. doi:10.2196/mental.5842

Şenormanc1, Ö., Şenormanc1, G., Güçlü, O., \& Konkan, R. (2014). Attachment and family functioning in patients with Internet addiction. General Hospital Psychiatry, 36(2), 203-207. doi:10.1016/j.genhosppsych.2013.10.012

Spada, M. M., \& Caselli, G. (2017). The metacognitions about online gaming scale: Development and psychometric 
properties. Addictive Behaviors, 64, 281-286. doi:10.1016/ j.addbeh.2015.07.007

Spada, M. M., Caselli, G., Manfredi, C., Rebecchi, D., Rovetto, F., Ruggiero, G. M., Nikčević, A. V., \& Sassaroli, S. (2012). Parental overprotection and metacognitions as predictors of worry and anxiety. Behavioural and Cognitive Psychotherapy, 40(3), 287-296. doi:10.1017/S135246581100021X

Spada, M. M., Caselli, G., \& Wells, A. (2009). Metacognitions as a predictor of drinking status and level of alcohol use following CBT in problem drinkers: A prospective study. Behaviour Research and Therapy, 47(10), 882-886. doi:10.1016/ j.brat.2009.06.010

Spada, M. M., Langston, B., Nikčević, A. V., \& Moneta, G. B. (2008). The role of metacognitions in problematic Internet use. Computers in Human Behavior, 24(5), 2325-2335. doi:10.1016/j.chb.2007.12.002

Spada, M. M., \& Marino, C. (2017). Metacognitions and emotion regulation as predictors of problematic Internet use in adolescents. Clinical Neuropsychiatry, 14(1), 59-63.

Spada, M. M., Mohiyeddini, C., \& Wells, A. (2008). Measuring metacognitions associated with emotional distress: Factor structure and predictive validity of the Metacognitions Questionnaire 30. Personality and Individual Differences, 45(3), 238-242. doi:10.1016/j.paid.2008.04.005

Spada, M. M., Nikčević, A. V., Moneta, G. B., \& Wells, A. (2007). Metacognition as a mediator of the relationship between emotion and smoking dependence. Addictive Behaviors, 32(10), 2120-2129. doi:10.1016/j.addbeh.2007.01.012

Statista.com. (2017). Facebook: Number of monthly active users worldwide 2008-2018. Hamburg, Germany: Statista.com. Retrieved from https://www.statista.com/statistics/264810/ number-of-monthly-active-facebook-users-worldwide/
Trinke, S. J., \& Bartholomew, K. (1997). Hierarchies of attachment relationships in young adulthood. Journal of Social and Personal Relationships, 14(5), 603-625. doi:10.1177/0265 407597145002

Valenzuela, S., Park, N., \& Kee, K. F. (2009). Is there social capital in a social network site?: Facebook use and college students' life satisfaction, trust, and participation. Journal of Computer-Mediated Communication, 14(4), 875-901. doi:10.1111/j.1083-6101.2009.01474.x

Valkenburg, P. M., \& Peter, J. (2011). Adolescents' online communication: An integrated model of its attraction, opportunities, and risks. Journal of Adolescent Health, 48(2), 121-127. doi:10.1016/j.jadohealth.2010.08.020

van de Schoot, R., \& Strohmeier, D. (2011). Testing informative hypotheses in SEM increases power: An illustration contrasting classical hypothesis testing with a parametric bootstrap approach. International Journal of Behavioral Development, 35(2), 180-190. doi:10.1177/0165025410397432

Wells, A. (2000). Emotional disorders and metacognition: Innovative cognitive therapy. Chichester, UK: Wiley.

Wells, A. (2013). Advances in metacognitive therapy. International Journal of Cognitive Therapy, 6(2), 186-201. doi:10.1521/ijct.2013.6.2.186

Wells, A., \& Cartwright-Hatton, S. (2004). A short form of the Metacognitions Questionnaire: Properties of the MCQ-30. Behaviour Research and Therapy, 42(4), 385-396. doi:10.1016/S0005-7967(03)00147-5

Wells, A., \& Matthews, G. (1996). Modelling cognition in emotional disorder: The S-REF model. Behaviour Research and Therapy, 34(11-12), 881-888. doi:10.1016/S0005-7967(96)00050-2

Willard, N. (2012). Cyber savvy: Embracing digital safety and civility. Thousand Oaks, CA: Corwin Press. 


\section{APPENDIX}

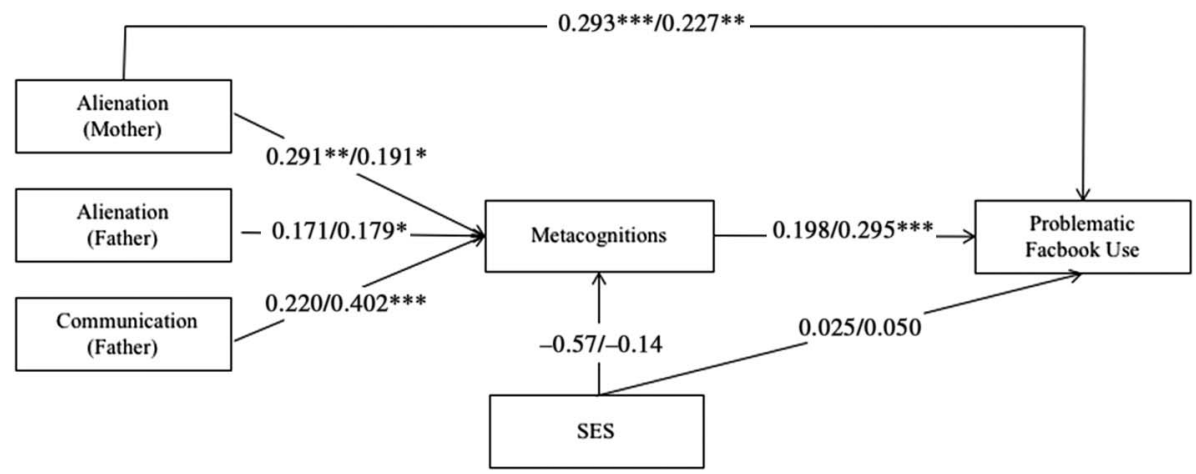

Figure A1. Multigroup analysis of the final model of problematic Facebook use (Study 1), showing the interrelationships between the variables in gender groups (boys vs. girls). Note. ${ }^{*} p<.05 .{ }^{* *} p<.01 .{ }^{* * *} p<.001$. Boys: $n=87$; girls: $n=184$

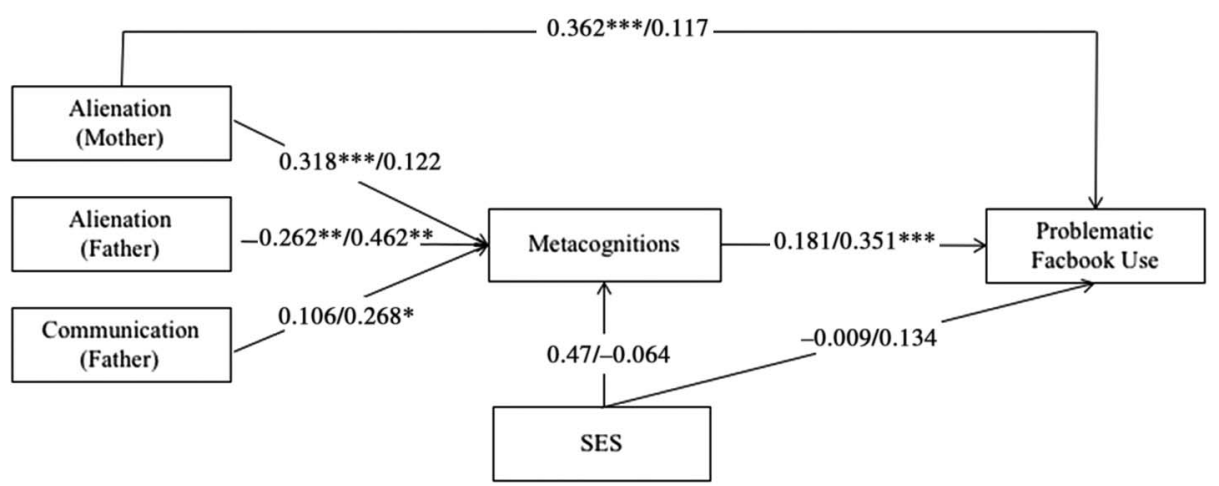

Figure A2. Multigroup analysis of the final model of problematic Facebook use (Study 1), showing the interrelationships between the variables in age groups (middle vs. late adolescents). Note. ${ }^{*} p<.05 .{ }^{* *} p<.01 .{ }^{* * *} p<.001$. Middle adolescents: $n=126$; late adolescents: $n=14$

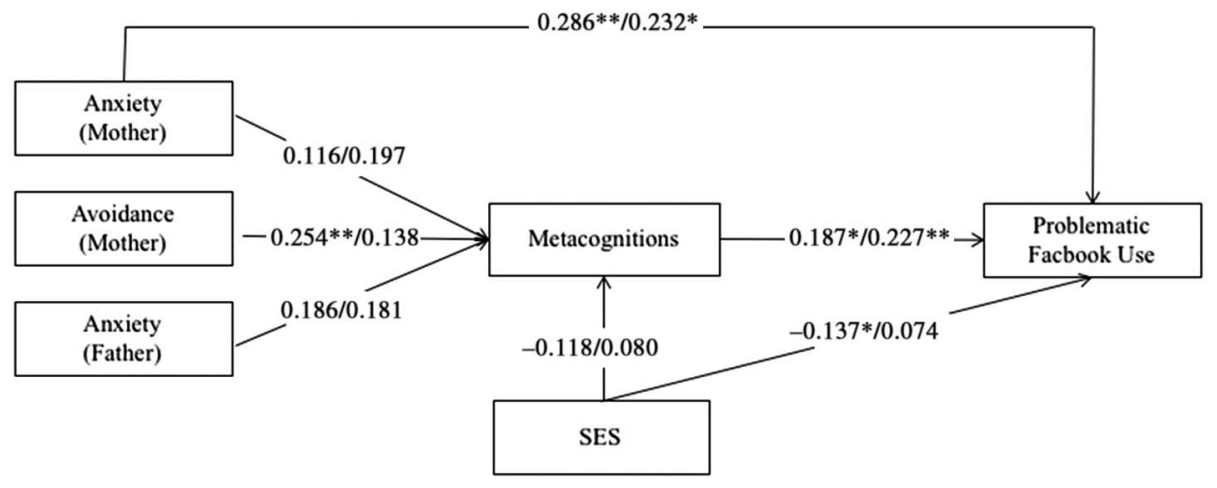

Figure A3. Multigroup analysis of the final model of problematic Facebook use (Study 2), showing the interrelationships between the variables in gender groups (boys vs. girls). Note. ${ }^{*} p<.05$. ${ }^{* *} p<.01$. Boys: $n=152$; girls: $n=184$ 
Marino et al.

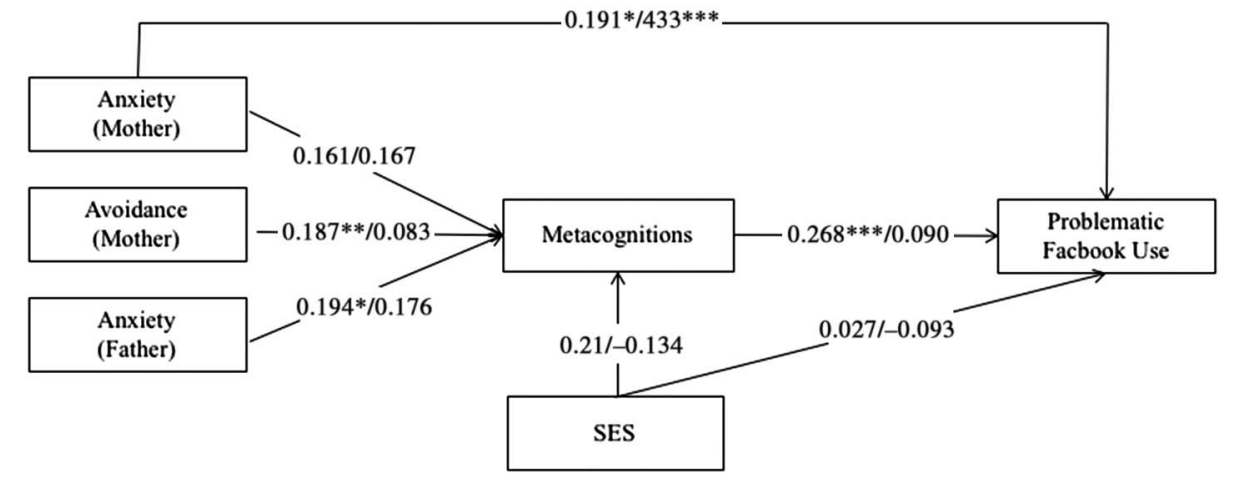

Figure A4. Multigroup analysis of the final model of problematic Facebook use (Study 2), showing the interrelationships between the variables in age groups (middle vs. late adolescents). Note. ${ }^{*} p<.05 .{ }^{*} p<.01$. ${ }^{* * *} p<.001$. Middle adolescents (14-16 years OLD): $n=224$; late adolescents (17-20 years OLD): $n=112$ 